\title{
Physics I MOOC - Educational Outcomes
}

\author{
David Lieberman*, Michael Dubson" ${ }^{\text {I }}$ Ed Johnsen" ${ }^{\text {II }}$ Jack Olsen ${ }^{\text {II }}$ and \\ Noah Finkelstein ${ }^{\text {I }}$
}

* Department of Physics, CUNY/Queensborough Community College, Bayside NY 11364
${ }_{\pi}$ Department of Physics, University of Colorado at Boulder, UCB 390, Boulder CO 80309

\begin{abstract}
While enrollment and retention figures often grab headlines for Massively Open Online Courses (MOOCs), the more telling measures of MOOCs' effectiveness may be found in the educational outcomes. The performance of students enrolled in the University of Colorado Physics I MOOC was evaluated with the use of numerous instruments. These instruments include exams, homework assignments, the FMCE and the CLASS. The performance of students in the MOOC was tracked across the semester and compared with that of students in similar "Brick and Mortar" classes at the University of Colorado. For some measures (FMCE) their performance was compared with the results from large scale studies. On all measures the MOOC students performed at least as well as and had learning gains at least as great as those in more traditional settings including interactive engagement. This may be due, in part, to a massive self-selection process skewing the MOOC population over time.
\end{abstract}

Keywords: PER, Introductory Physics, MOOC, FMCE, CLASS

PACS: 01.40.Fk, 01.50.H-

\section{INTRODUCTION}

Massively Open Online Courses (MOOCs) are often praised for their ease of access (large enrollments) or criticized for their low retention (completion) rates. While enrollment and retention figures are what often grab headlines, the more telling measures of MOOCs' effectiveness may be found in the educational outcomes. This paper describes an attempt to evaluate a MOOC's effectiveness by studying educational outcomes.

In the fall of 2013, the University of Colorado at Boulder offered a Massively Open Online Course (MOOC) titled "Physics I for Physical Science Majors" through Coursera approximately in parallel with the university's calculus-based physics one course for engineering and physics majors (Phys 1110). The MOOC began two weeks after Phys 1110 and because the pace was the same stayed two weeks behind. While online and in-person environments are not the same, the MOOC and Phys 1110 had much in common [1]. The lectures for the MOOC were videorecorded versions of the Phys 1110 lectures with dead time edited out and concept tests from the lectures ("clicker" questions) edited in. The homework assignments were, for the most part, identical to the Phys 1110 assignments as were the exams. The major differences between the MOOC and Phys 1110 were the use of tutorial-based recitation sections and peer discussion during concept tests [2] in Phys 1110 and the use of discussion forums in the MOOC. The discussion forums were not meant to replace recitation. They were a place where students could discuss topics related to the course such as lectures and homework problems. Course instructors monitored the forums but kept their interaction to a minimum. These forums were primarily for peer interaction not for "office hours" or for tutorials.

The performance of students enrolled in the MOOC was evaluated with the use of numerous instruments. The instruments used were homework assignments, exams, the FMCE [3] and the Colorado Learning Attitudes about Science Survey (CLASS) [4]. Student performance was tracked across the semester and compared with students in Phys 1110 for all measures except the CLASS. The performance of students in the MOOC was also compared with the results for large scale studies, specifically those for the FMCE and CLASS. By all of these measures MOOC students performed at least as well as and had learning gains at least as great as those in more traditional settings.

It should be noted that 708 students completed Phys 1110 (out of 799) while only 225 students completed the MOOC (out of 15,996). While this large scale attrition was going on in the MOOC a massive self-selection process was occurring skewing the population over the duration of the course. This 
may, to some measure, be responsible for the high level of performance in the MOOC.

\section{MOOC VS. PHYS 1110}

As noted above, the students enrolled in the MOOC and students enrolled in Phys 1110 had, for the most part, identical homework assignments and exams, but there were some differences. The syllabus for the MOOC only covered the first 12 weeks of the Phys 1110 syllabus which meant that performance on final exams from both courses could not be compared.

There were three exams and a final administered in Phys 1110 and two exams and a final in the MOOC. The three Phys 1110 exams spanned the topics covered in the MOOC and did not include questions on topics not covered by the MOOC. In order to have a comparison of performance on all three exams, the final exam for the MOOC consisted of a set of questions identical to all of the questions on the third Phys 1110 exam (25 questions) plus an additional 15 questions on earlier material. When the MOOC final exam was scored, the part identical to the third Phys 1110 exam was scored separately and is designated as the MOOC exam 3 for all analysis. Another issue that needed to be addressed is that the MOOC students were given multiple attempts for each exam. While each attempt was timed so that MOOC students had no more time than Phys 1110 students, MOOC students could attempt the exam a second or third time, allowing them to increase their scores. In some cases students used their first attempt only to view the exam and achieved a score of zero as they did not answer any questions. In order to eliminate both behaviors from affecting the results, only first valid attempts were used in our analysis. As these were multiple choice exams with no penalty for guessing any attempt with fewer than five questions answered was considered invalid.

The fact that the MOOC only covered the same material as the first twelve weeks of Phys 1110 meant there were only 12 homework assignments in the MOOC. These assignments were identical to those for Phys 1110. If a student, either MOOC or Phys 1110 , did not submit an assignment, the zero was not included in the analysis although it did affect the student's grade.

Students in Phys1110 were administered the FMCE in class at the start of the course (pretest) and again at completion of the course (posttest). For students in the MOOC the FMCE was administered online as surveys and students were given a time window in which to complete it at the beginning of the course (pretest) and near the end of the course (posttest). For MOOC students credit (points toward successful course completion) was given for completing surveys. Of those who completed the course, approximately $55 \%$ of MOOC students took both the pre and post tests, while for Phys 1110 it was closer to $65 \%$.

As table I shows, the students who completed the MOOC performed at least as well as those who completed Phys 1110 on all measures. The MOOC students scored better on the exams and statistically the same on the homework, 89.3( \pm 0.5$)$ for the MOOC versus $88.7( \pm 0.3)$ for Phys 1110 . Their normalized gains on the FMCE were comparable as well, $0.58( \pm 0.047)$ for the MOOC versus $0.59( \pm 0.033)$ for Phys 1110.

Table I. Average scores on individual homework assignments and exams and normalized FMCE gains for students who completed the MOOC $(\mathrm{N}=225)$ and students who completed Phys 1110 (N=708).

\begin{tabular}{|c|c|c|}
\hline & MOOC & Phys 1110 \\
\hline Homework 1 & 97.7 & 94.4 \\
\hline Homework 2 & 90.5 & 90 \\
\hline Homework 3 & 90.3 & 87.6 \\
\hline Homework 4 & 94.6 & 90.2 \\
\hline Homework 5 & 89.1 & 89.8 \\
\hline Homework 6 & 90 & 90.4 \\
\hline Homework 7 & 89.2 & 83.4 \\
\hline Homework 8 & 90.4 & 87.7 \\
\hline Homework 9 & 87.1 & 89.9 \\
\hline Homework 10 & 84.9 & 82.2 \\
\hline Homework 11 & 82.9 & 86.2 \\
\hline Homework 13 & 84.8 & 93.1 \\
\hline Exam 1 & 83.4 & 75.1 \\
\hline Exam 2 & 79.8 & 68 \\
\hline Exam 3 & 74.9 & 68.2 \\
\hline FMCE normalized gain & .58 & .59 \\
\hline
\end{tabular}

\section{FMCE and CLASS}

As noted above, students completing the MOOC perform favorably when compared to Phys 1110. In order to place their performance within the broader realm of physics classes, the FMCE was used as a measure of learning gains and the CLASS was used to measure changes in attitudes towards physics. As with the FMCE pre and post CLASS were administered online as surveys.

Large-scale studies [5,6] have used both the FMCE and the Force Concept Inventory to measure learning 
gains with the understanding that the two instruments yield similar results [7]. In Hake's [5] large scale study no distinction was made between different types of interactive engagement while Pollock [6] separates interactive engagement in lectures alone from interactive engagement in lectures and the use of tutorials in recitation. In both cases traditional lectures yield normalized gains of less than 0.30 (Hake[5] reports an average of $0.23( \pm 0.04)$ for traditional lecture and $0.48( \pm 0.14)$ for interactive engagement). In both studies the highest normalized gains are approximately 0.70. The MOOC outperforms traditional lecture classes by a wide margin. It outperforms most classes with lectures incorporating interactive engagement. If compared only to classes incorporating both interactive engagement in the lectures and tutorials in recitations, the MOOC would still be placed in the upper half.

As measured by the CLASS, typical physics classes including those incorporating interactive engagement in lectures and/or recitation (such as PHYS110), do not improve students' attitudes towards physics and in many cases have a negative impact on those attitudes [4]. As table II shows, the opposite is true for the MOOC. For students completing the MOOC CLASS scores improve and in some categories improve by more than two standard errors.

TABLE II. CLASS pre, post and shifts for the physics MOOC and shifts for typical classes including those with interactive engagement. The survey consists of 36 questions for the overall and 26 total for the various categories. A more complete description can be found in Adams et al [4]. Positive attitudes are indicated by high favorable percentages and low unfavorable percentages. Only favorable responses are included in the table. Positive shifts indicate a positive shift in attitudes. The typical shifts are from Adams et al. [4].

\begin{tabular}{|l|c|c|c|c|c|}
\hline & PRE(\%) & POST(\%) & SHIFT(\%) & Std Err & Typical Shift \\
\hline Overall & 71.1 & 72.9 & 1.8 & 0.9 & -6 \\
\hline All categories & 72.9 & 75.5 & 2.5 & 1.0 & \\
\hline Personal Interest & 79.9 & 82.2 & 2.3 & 1.6 & -11 \\
\hline Real World Connection & 79.7 & 82.1 & 2.4 & 1.6 & -7 \\
\hline Problem Solving General & 77.6 & 82.1 & 4.5 & 1.4 & -13 \\
\hline Problem Solving Confidence & 71.3 & 78.5 & 7.2 & 2.0 & -15 \\
\hline Problem Solving Sophistication & 64.1 & 68.0 & 3.8 & 2.0 & -15 \\
\hline SensesMaking/Effort & 80.6 & 81.5 & 0.9 & 1.4 & -10 \\
\hline Conceptual understanding & 69.8 & 72.6 & 2.9 & 1.8 & -8 \\
\hline Applied Conceptual understanding & 58.0 & 60.2 & 2.3 & 1.9 & -6 \\
\hline
\end{tabular}

\section{SELF-SELECTION}

Students who completed the MOOC are not typical in many ways $[1,8]$. The demographics of students who completed the MOOC have been studied and compared with those completing Phys 1110 and are reported elsewhere [8]. In general the MOOC students were older and more educated than the PHYS1110 students. The average age of students at the start of the MOOC was 31.5 years old and $58 \%$ has at least a bachelor's degree. That being said, at the start of the course the FMCE pretest scores for the MOOC and PHYS1110 were the same and CLASS pretest scores were consistent with those of a typical PHYS1110 class. Regardless of their demographics MOOC students are different in another way. Over the course of the semester they go through a process of self-selection so that the best performers complete the course (for the most part). As shown in table III, in all measures (Exam scores, FMCE pre, CLASS) the average scores of students who were still on track to complete the course improved at each stage (exam 1, exam2, completion). Another view of the self-selection process is the shift in the FMCE pretest score distribution, figure 1.

TABLE III. Average scores (out of 100), for all MOOC students still active at each stage in the course.

\begin{tabular}{|l|r|r|r|r|}
\hline & \multicolumn{1}{|l|}{$\begin{array}{l}\text { FMCE } \\
\text { pre }\end{array}$} & \multicolumn{1}{l|}{$\begin{array}{l}\text { CLASS } \\
\text { pre }\end{array}$} & Exam 1 & Exam 2 \\
\hline start & 40.1 & 68 & & \\
\hline exam 1 & 57.86 & 69.69 & 74 & \\
\hline exam 2 & 63.68 & 70.97 & 84 & 73.98 \\
\hline completion & 65.99 & 71.37 & 84.5 & 78.4 \\
\hline
\end{tabular}




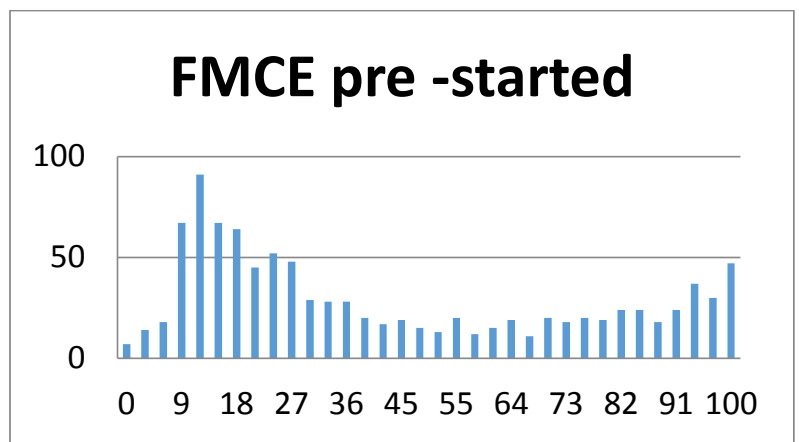

\section{FMCE pre - completed}

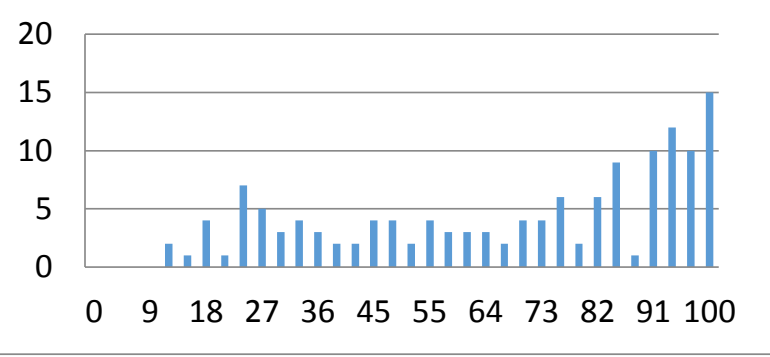

FIGURE 1. MOOC FMCE pre-test distributions. Top: all students who took the FMCE pre. Bottom: all students who took the FMCE pre and completed the course. Note the elimination of most of the very low scores and the shift of the distribution such that the mode is 100 for those who complete the course. The yaxis indicates the number of students and the $\mathrm{x}$-axis the FMCE score in percent.

\section{CONCLUSIONS}

MOOC students who complete the course have learning gains that are as high as one would expect from the best on-campus classes, but are those gains due to the course environment and structure or due to the specific students? The self-selection process implies that it may well be due to the specific students However, the learning gains, such as the increase in FMCE scores, exceed those of traditional lecture courses, even when the self-selection process is taken into account. Another factor is the demographics of the successful MOOC students. Their age, experience and level of education may be the reason for their success. While more study is needed, the results reported in this paper indicate that MOOCs may be a great method of course delivery to a select few but they are a poor choice for most students.

\section{ACKNOWLEDGEMENTS}

This work was supported by the CU Offices of the Associate Vice President for Digital Education and Engagement, the CU Office of Vice President for Academic Affairs, the CU system Office of the Executive Vice Chancellor for Academic Affairs, and the CU Center for STEM Learning.

\section{REFERENCES}

1. M. Dubson, N. Finkelstein, D. Lieberman and E. Johnsen, Presented at the American Association of Physics Teachers Summer Meeting, Minneapolis(2014)

2. N.D. Finkelstein \& S.J. Pollock, Physical Review Special Topics - Physics Education Research, 1 (2005).

3. R.K. Thornton \& D.R. Sokoloff, American Journal of Physics, 66(4), 338-352. (1998).

4. W. Adams, K. Perkins, N. Podolefsky, M. Dubson, N. Finkelstein and C. Weiman, Phys. Rev. Special Topics Phys. Educ. Res. 2, 010101 (2006)

5. R. Hake, Am. J. Phys., Vol. 66, No. 1, January 1998.

6. S. Pollock and N. Finkelstein, Phys. Rev. Special Topics - Phys. Educ. Res. 4, 010110 (2008).

7. Thornton, Kuhl, Cummings and Marx, Phys. Rev. Special Topics - Phys. Educ. Res. 5, 010105, (2009).

8. J. Olsen, M. Dubson, N. Finkelstein, K. Goodman, E. Johnsen and D. Lieberman, Presented at the American Association of Physics Teachers Summer Meeting, Minneapolis(2014) 